\title{
A cross-cultural study of musical grammar and its relation to affective expression in two musical idioms between Chennai and Geneva
}

\author{
Constant Bonard ${ }^{1}$
}

"Etoit-il étonnant que les premiers Grammairiens soumissent leur art à la Musique, \& fussent à la fois professeurs de l'un \& de l'autre?" Rousseau, Essai sur l'origine des langues ${ }^{2}$

Can music be considered a language of the emotions? The most common view today is that this is nothing but a Romantic cliché. Mainstream philosophy seems to view the claim that 'Music is the language of the emotions' as a slogan that was once vaguely defended by Rousseau, Goethe, or Kant, but that cannot be understood literally when one takes into consideration last century's theories of language, such as Chomsky's on syntax or Tarski's on semantics (Scruton 1997: ch. 7, see also Davies 2003: ch. 8, and Kania 2012). In this chapter, I will show why this common view is unwarranted, and thus go against nowadays philosophical mainstream by defending what I call the musicalanguage hypothesis ${ }^{3}$.

In Section 1, I will introduce the musicalanguage hypothesis and present, based on empirical evidence, some of the many similarities between language and music and explain why we should take them seriously. I will introduce a framework that aims to explain the communicative power of music using what we already know about linguistic communication

\footnotetext{
${ }^{1}$ Thanks to K.G. Vijayakrishnan, Rajshri Sripathy, Ramani Narayanan, Lalitha Raghavan, and G.Ravindran, for helping me design and run the test in India, to Patrik Dasen for helping me run the test in Geneva, to the anonymous referee for helpful comments, and to Florian Cova for the last minute statistical analysis and helpful comments.

${ }^{2}$ Cited in Katz and Pesetsky (2011).

${ }^{3}$ A note for those interested in the philosophy of language: I agree with Davies' (2003: ch. 8) point that musical meaning is neither propositional (propositions understood as the primary bearers of truth and falsity), nor conceptual (concepts being understood as the essential constituents of propositions and as the arguments of logical structures). Music is thus, strictly speaking, unapt for a truth-conditional semantics, unlike verbal languages. This doesn't mean it is unapt for a 'super-semantics' (Schlenker, forthcoming). Compare: Most (if not all) non-human animal communication supposedly is neither propositional nor conceptual, but as Schlenker argues, something like a truth-conditional semantics can be developed to analyze their communication.
} 
(1.1). I will then outline several working hypotheses about musical grammar, musical meaning, and affective meaning (1.2), and thus defend that music is indeed very close to literally be a language of the emotions.

In Section 2, I will detail some of the methodology, expectations, and preliminary results of a cross-cultural study on musical grammar that I am presently conducting between South India (Chennai) and Switzerland (Geneva and Lausanne) ${ }^{4}$. This empirical study focuses on two musical idioms and their grammatical features: Western classical music of the Common Period (ca. 1600-1900) and South Indian classical music (also know as Carnatic music). The main hypothesis of this study is that you need to master the grammar of a musical idiom in order to properly understand its musical meanings.

\section{Music, language, and affective meaning: Background theory}

\subsection{Introducing the 'Musicalanguage' hypothesis.}

In the last three or four decades, especially since Lerdahl and Jackendoff's (1983) seminal book A Generative Theory of Tonal Music, more and more works in cognitive science have been interested in using the comparison between music and language to understand how music achieves communication, especially of emotions ${ }^{5}$. Now, of course, none of these cognitive scientists would argue that music is a language like English or French. The main issue rather is: How much of the cognitive apparatus that makes up the language faculty overlaps with the cognitive apparatus making up the music faculty? Some people, like I, would tentatively answer: "A very significant part, and at all levels of analysis, from the cognitive mechanisms dealing with smallest units of sounds up to the ones dealing with the most complex linguistic and musical productions." Music would thus make use of cognitive mechanisms used in phonetics, phonology, prosody, syntax, semantics, and pragmatics. I call this idea the 'musicalanguage' hypothesis (see Figure 10.1).

\section{Figure 1. The musicalanguage hypothesis.}

\footnotetext{
${ }^{4}$ The data is still being analyzed as I write this chapter.

${ }^{5}$ For an in-depth and very competent discussion, see Patel (2010).
} 


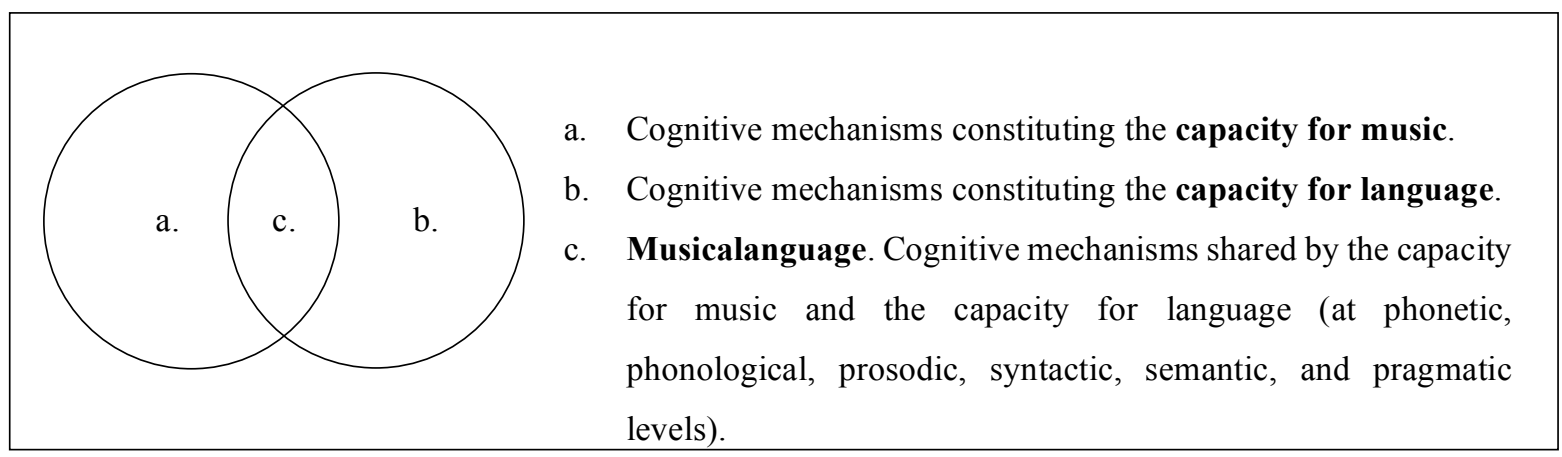

One of the most central claims of the musicalanguage hypothesis concerns musical grammar and, especially, the nature of musical syntax and its relation to musical meaning. It is now widely accepted that the perception of melodies, harmonies, and rhythms (and hence musical understanding) is grounded in our capacity to form mental representations of musical structures that are hierarchically organized, some notes being structurally more important than others (see e.g. Brown et al. 2006, Granroth-Wilding and Steedman 2014, Katz and Pesetsky 2011, Koelsch and Siebel 2005, Kunert et al 2015, Patel 2010, Rohrmeier and Neuwirth 2015, Schlenker forthcoming, Vijayakrishnan 2007). This mental organization is very similar to the one operating in linguistic syntax and can be represented by the same trees that linguists use to represent the syntactic organization of sentences. It can also be formalized by the same conceptual tools ${ }^{6}$. It is noteworthy that, based on the theoretical similarities in musical and linguistic syntactic organization, neuroscientists have shown that identical regions of the brain (including Broca's area and its right hemisphere homolog) are used to process both linguistic syntax and musical syntax (Koelsch 2005, Brow, Martinez and Parsons 2006, Patel 2010, Kunert et al. 2015). Similar works are also happening in psycholinguistics (e.g. Van de Cavey and Hartsuiker 2016). This thriving area of research, which goes far beyond the few examples given here, is especially interesting for us in light of the fact that some eminent language researchers such as Chomsky consider the capacity for syntax to be the only essential feature of our language faculty (see Hauser, Chomsky and Fitch 2002), which would allow an almost literal reading of our Romantic slogan.

Moreover, musical semantics tasks (e.g. such as priming tasks) have also been found to require brain activities that have previously been linked with linguistic semantics (the famous N400 response, long thoughts to be activated only with word-stimuli, has been observed with

\footnotetext{
${ }^{6}$ In the technical terminology of MIT linguistics, Katz and Pesetsky (2011) argue that musical syntax, just as linguistic syntax, yields headed structures generated by an iterated binary Merge.
} 
musical extracts, see Koelsch and Siebel 2005). Recently, a program has been launched to establish a formal semantics for music, inspired by truth-conditional semantics (Schlenker forthcoming). Research on the musical equivalents of phonology, prosody, or pragmatics has also flourished (see for instance Rebuschat et al. 2012). All in all, a cognitive science reinterpretation of the Romantic cliché that music is a language of the emotions should be taken seriously. This claim will echo in the background of this whole chapter.

\subsection{Musical grammar: a working hypothesis}

It should not be controversial that there is such a thing as musical grammar for someone who accepts the existence of musical meaning and thinks that grammar (in general) is a cognitive mechanism that mediates between raw sounds (mutatis mutandis gestures or written signs) and meaningful entities, which is a common, if rather loose, way of characterizing grammar in linguistics $^{7}$ (see Figure 10.2). Grammar is thus considered here as a higher-order cognitive mechanism that brings together smaller cognitive mechanisms pertaining to phonetics, phonology, morphology, semantics, and syntax. Let me briefly detail these general points about grammar by illustrating five points that are common to verbal and musical grammars.

\section{Figure 10.2. A characterization of grammar working for both music and language according to the musicalanguage hypothesis.}

\section{Grammar}

\section{Phonetics}

Phonology

Sounds

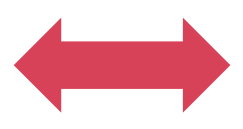

Prosody

Semantics

Syntax

Pragmatics

\footnotetext{
${ }^{7}$ Such a characterization can be commonly found in linguistics textbook such as O'Grady et. al (2017). I would have preferred giving a more precise characterization but, alas, being loose unfortunately seems to be a prerequisite for someone who, like I, do not want to exclude a priori either generative or cognitive linguistics.
} 
The grammar of a given verbal language allows one (i) to parse a sequence of sounds into relevant discrete elements (e.g. phonemes, words) that (ii) are abstracted from the inevitable physical contingencies (e.g. one phoneme token can be instantiated by different physical sounds), (iii) ignoring irrelevant sounds (e.g. a lisp). This allows one to (iv) fit these discrete elements together into larger, meaningful units (e.g. sentences, arguments). It also allows one (v) to convey, express, or share something with others through a sequence of meaningful sounds. How exactly linguistic grammar should be described is a hotly debated question (see e.g. Domardzki 2007). Should it be through rules (Chomsky), preference constraints (Prince), constructions (Goldberg), schemas (Lakoff), or in another way? There is no consensus here. However, linguists do agree that a specific grammar yields structural constraints on the formation of acceptable (or natural) sentences and that part of the linguist's job is to make explicit the implicit knowledge we have of these.

Accordingly, the grammar of a given musical idiom allows one (i) to parse a sequence of sounds into relevant discrete elements (e.g. notes, motifs) that (ii) are abstracted from the inevitable physical contingencies (e.g. one note token can be instantiated by different physical sounds), (iii) ignoring irrelevant sounds (e.g. the 'buzz' of an amplifier). It also allows one to (iv) see how these elements fit together into larger, meaningful units (e.g. melodies, variations). Like the grammar of languages, musical grammar also allows one to convey, express, or share something with others through a sequence of meaningful sounds. Given a certain musical style or idiom, a musical grammar also yields structural constraints on the formation of acceptable (or natural) sentences, including polyphonic sentences (different melodies that are composed to sound well together). Thus, most composition text books largely deal with grammatical issues - at least the ones whose purpose is to formulate explicitly the knowledge of the structural constraints that a composer in that style possesses implicitly. Harmony and counterpoint textbooks thus somehow are the musical equivalents to syntax textbooks we use to learn such or such language.

That being said, linguistic and musical meanings differ so importantly that one might think that talk of musical meaning and musical grammar is merely metaphorical. This is not the place to properly argue for the claim that meaning in music is genuine. What meaning is in language is already a vexed and hotly contested question. One thing that seems secure enough to claim though, is that meaning, in both music and language, is intrinsically linked with understanding and expression. This is an insight that has been present in most, if not all, philosophy of language since Frege, as stressed by Dummett (1973). Now, when we say that 
someone has misunderstood a musical passage or that such or such person has succeeded in expressing something in a musical composition, these are not mere metaphors.

Still though, even if the existence of expression and understanding in music is recognized, one might remain skeptical about genuine musical meaning. What makes it particularly difficult to argue against such skepticism is that, if there is such a thing as musical meaning, it must be ineffable (see Raffman 1993). To give a quick example, in order to understand what Beethoven has conveyed in the Heiliger movement of his $15^{\text {th }}$ quartet, it is not enough to understand that he expressed his gratitude to the divinity for recovering after a grave illness, although he stated that this is what the piece is about in the piece subtitle. This factual knowledge can be grasped by someone who is deaf to his music. In order to understand the musical expression, one needs to do so through the very notes that Beethoven composed. This meaning cannot be verbalized. ${ }^{8}$

But a question remains: What exactly is affective meaning in music? I can only briefly say a word about this topic before we go on with the description of the experimental study. To give a simple answer that shouldn't be controversial, we can say that the affective meaning of a musical piece is what one would want to know when asking 'What does this music express?'. We could also say, with Stephen Davies, that "it is whatever it is that we understand when we (can be said by others to) understand a musical work aesthetically." (Davies 2003: 121)

In the following, I will not only accept this definition but also endorse a stronger claim and characterize musical affective meaning in a more pragmatic way. Following the line of thought inherited by ordinary language philosophy (as in Grice 1957, Strawson 1950, or Wittgenstein 1953), I will adapt to music another slogan: 'Meaning is use'. I will assume that the affective meaning of a musical extract $\mathrm{E}$ of the musical idiom MI corresponds to what competent listeners of MI agree E expresses. Well-trained musicians of MI are here considered as competent listeners.

So, for the remainder of this chapter, think of musical grammar as a cognitive mechanism that takes raw sounds as input and affective meaning as output thanks to a

\footnotetext{
${ }^{8}$ For some, this just shows there is no real meaning here. This is not the place to argue against such a view. For arguments that Western instrumental music can have proper meaning, see for instance Davies (2003), Levinson (2011), Schlenker (forthcoming), or Scruton (1997), and, for Carnatic music, Vijayakrishnan (2007). In the following, we will thus assume that what we call affective meaning is a plausible candidate for the output of a musical grammar in both these traditions.
} 
hierarchical, norm-following structural organization that parses raw sounds. Let us now turn to the description of the experiment.

\section{Description of the empirical study 'Perception and Expression in South Indian and Western Classical Music'}

\subsection{Main aims}

Here are the two main questions that are being tackled in this study:

(1) Perception of musical structure. Given that different musical idioms have different tonal organizations based on different grammatical structures, would a listener who is familiar with musical idiom MI1, but not with musical idiom MI2, be better than average at perceiving musical structures that respect the grammatical organizations of MI1, but not of MI2? To take an example: if you have listened to a lot of South Indian music and I haven't, would you be better than I at recognizing South Indian melodies? Will you hear the notes, so to say, more distinctly, and thus be able to detect differences in two melodies that will sound the same to me? The hypothesis here is that the answer will be "Yes" to both questions.

(2) Perception of musical expression. Would a listener who is better at perceiving musical structures from MI1 than from MI2 be also better at telling what is expressed in musical pieces of MI1? To illustrate: if you are better at recognizing South Indian melodies, and hear their notes more distinctly, will you also be better than me at understanding what the musicians/composers wanted to express in South Indian music? I have the intuition that the answer should be "Yes" here too. The main predictive hypothesis here is that, in order to better understand what is being expressed in a musical idiom, one needs to have developed its musical grammar to a sufficient level. ${ }^{9}$

\footnotetext{
${ }^{9}$ Since this chapter belongs to a book on experimental philosophy and that what I have said up to this point primarily comes from psychological and musicological sources, it might be worth at this point listing a few of the philosophical questions that are relevant to the present study: Can music communicate anything objectively or do
} 
The main goal of this study thus is to empirically explore how one's familiarity with a given musical idiom affects (1) one's perception of musical structures and (2) the understanding of musical expression in this idiom. The experiment has thus been designed to measure differences and commonalities in populations with varying degrees of familiarity to two musical idioms.

\subsection{The grammars of Western classical music and South Indian classical music}

The two idioms are Western classical music and South Indian classical music (also called Carnatic music). They have been chosen because they are among the only ones whose grammars are described in book-length theoretical works: for South Indian classical music, Vijayakrishnan's The Grammar of Carnatic Music (2007) and for Western classical music, for instance, Lerdahl's Tonal Pitch Space (2001).

Let me briefly talk about some grammatical commonalities and differences between Western classical and Carnatic musical grammars. In both these idioms, pieces are composed according to principles of tonality: they are tonal idioms ${ }^{10}$. Very roughly, this is the idea that, given a melody, there are some notes that are structurally more important than others, that are the tonal centers, and toward which other notes of that tonality revolve. Atonal melodies, melodies in which there are no perceivable tonal centers, then are ungrammatical in both idioms.

Both musical idioms are also modal ${ }^{11}$ in the sense that their tonal principles are defined by modes. A musical mode is basically a finite set of notes (usually 5 to 9 notes) from which melodies and harmonies are constructed. More precisely, modes are defined by the musical intervals that they allow. A basic principle of tonality is that, given a musical mode, the most important note is the tonic.

we just project our personal opinions onto the music? How can music be meaningful given that it is only abstract patterns of sound? What is the difference between linguistic meaning and musical meaning? Can we speak literally of musical grammar? What does it take to be a competent listener of a given musical idiom? Of course, these questions, which have been discussed by philosophers for centuries, are not going to find a definite answer here. The main purpose of this chapter is to show how empirical studies help us to take fresh look at them while supporting or debunking some philosophical claims.

${ }^{10}$ In the broad sense of the term, which doesn't imply functional harmony.

${ }^{11}$ Here, in order to simplify terminology and comparison between the two idioms, I use the word 'mode' in a broad way and don't distinguish between melodic modes, harmonic modes, scales, and tonality. This also allow me to talk of raagam as modes. 
Let us give some examples from Western music. In both the modes of $\mathrm{C}$-major and $\mathrm{C}$ minor, the tonic is $\mathrm{C}$. The next most important notes in these modes is $\mathrm{G}$ (whose interval to the tonic is a perfect fifth). Now C-major uses the note $\mathrm{E}$ (interval of major third) while $\mathrm{C}$-minor doesn't and replace it with the note $\mathrm{Eb}$ (minor third). Neither of these modes uses the note $\mathrm{Gb}$ (interval of tritone, or diminished fifth). Western classical music is made of only three modes: the major, natural minor, and harmonic minor modes. The first two makes use of 7 of the 12 notes available in Western classical music (i.e. the 12 notes making up the white and the black keys of piano) and the harmonic minor mode uses 8 (e.g. the mode $\mathrm{C}$ harmonic minor demands an A when the melody goes up and Ab when it goes down). Typically, in a piece of Western classical music, the music changes from one mode to another. This is called a modulation. Modulations in Western classical music is very common (there are modulations in virtually every piece), but it is highly regulated. A grammatical principle of Western classical music then is that one cannot switch from one mode to another randomly, one must respect the rules governing modulation.

Carnatic music also is made of melodic modes, called raagam (singular: raaga). In fact, it is made of 72 different raagam - 69 more modes than in Western music! Raagam are not only differentiated by which notes belong to the raaga, but, among other things, by which melodic movements are authorized or not. As with Western modes, the tonic is the most important note in a raaga, but, unlike Western classical music, the perfect fifth may or may not be the second most important one (the perfect fifth is in fact absent in many raagam). As in Western musical modes, there is a total of 12 notes that make up the different raagam, which are roughly the same as the black and white keys of a piano (not quite as Carnatic music tends to use just intonation tuning). Just like Western modes, raagam select a certain number of notes (between 5 and 9) from these 12. Unlike Western music though, Carnatic music can add up to 10 more 'embellishment notes' called shruti ${ }^{12}$. Shruti are micro-tonal intervals, with no fix pitch, which ornament the notes making up the different raagam.

A very important difference between the grammars of Western and Carnatic music is that, in the latter, modulations are not allowed: one must stick to only one raaga during a piece of Carnatic music. Another important difference between the two musical grammars is that Carnatic music uses many raaga that do not fit in the Western minor/major modes. For instance,

\footnotetext{
${ }^{12}$ The number of shruti is a controversial question, see Datta et al. 2006.
} 
the raaga called Bhairavi uses the equivalents to $\mathrm{C}, \mathrm{Db}, \mathrm{Eb}, \mathrm{F}, \mathrm{G}, \mathrm{Ab}$, and $\mathrm{Bb}$, a mode which sounds very foreign to our ear.

These two grammatical differences are the main ones on which I and K.G. Vijayakrishnan have based the stimuli in the part of the experiment described in section 2.4. below.

\subsection{General procedure}

Participants $(n=78)$ have been recruited according to their familiarity with the two musical idioms. They either come from India $(n=38)$, or from Europe $(n=40) .55$ considered themselves music practitioners, that is either amateur musicians, semi-professional musicians, or professional musicians. 24 considered themselves non-musicians or music lover nonmusicians. 48 were females and 31 males. In India, participants were recruited at the University of Chennai (in classes of Carnatic music and of journalism). In Switzerland, they, for the most part, were students of the Haute Ecole de Musique de Genève or of the University of Lausanne and $\mathrm{EPFL}^{13}$.

Participants sat together in a room and were asked to fill out a paper questionnaire while listening to musical stimuli through loudspeakers. The questionnaire also included a survey on general background information, musical education, and on participants' listening habits with respect to classical and non-classical Western music, Carnatic and Indian music in general. After the survey, the experiment came in three parts. For lack of space, the first part of the experiment, on felt emotions, cannot be presented here. ${ }^{14}$

\subsection{First Hypothesis: familiarity and the perception of melodic and rhythmic structures}

In this part, our aim was to test how participant's familiarity with the two musical idioms affects their perception of musical structures. The musical structures in question were designed to either fit in or to not fit in the grammar of the two musical idioms.

\footnotetext{
${ }^{13}$ It should already be noted though that, because Western music has been increasingly present in South India through mass-media and cultural globalization, especially in urban environments such as that of Chennai, there should be an asymmetry between Western and South Indian subjects. Even if it is mostly Western popular musics rather than Western classical music that has spread to India, we can expect an asymmetry as Western popular music has widely borrowed its harmonies, melodies, and rhythms from Western classical music.

${ }^{14}$ It will be presented in Bonard, Vijayakrishnan, and Grandjean (in preparation).
} 
The rationale for this part is the following: It is known that, for Western subjects, atonal melodies are more difficult to encode/memorize/perceive/compute compared to tonal ones (Dowling et al. 1995, Schulze et al. 2012, Law and Zentner 2012). The musicalanguage explanation for this phenomenon is the following: in both music and language, we have more difficulty computing utterances that are ungrammatical in idioms with which we are familiar, and atonal melodies do not respect the syntax of Western tonal music, the idiom with Westerners are most familiar. This is why they find atonal melodies harder to recognize.

To test this hypothesis as applied to Carnatic vs. Western classical music, K.G. Vijayakrishnan and I have designed stimuli that were supposed to either fit in or not to fit in the grammar of the two musical idioms. I then tested how well participants were able to perceive them accurately.

To do so, I used the PROMS (PRofile of Musical Skills) framework. PROMS is a test to measure musical perception skills (Law and Zentner 2012). The paradigm is the following: subjects are presented (twice) with a first musical stimulus (ca. 2-3 seconds long), called the reference stimulus, before being presented with a second stimulus, called the comparison stimulus. The comparison stimulus is either the same as the first, or slightly different (e.g. one note of a melody is one tone lower). Participants' task is to judge whether they perceive the reference and the comparison stimuli to be the same, different, or whether they don't know, as illustrated in Figure 10.3 below.

Figure 10.3. The PROMS framework.

\section{SYNTHETIC MELODY TEST}

$8 / 22$

Please wait until you hear 3 sound clips before choosing an answer.

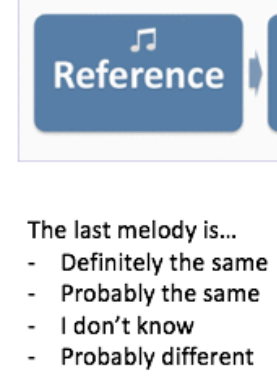


Participants had to answer 50 trials: 10 with rhythms and 40 with melodies. For half of these 50 trials, the comparison stimulus were the same as the reference stimulus, while there was a change in the comparison stimulus for the other half. The 10 rhythmic trials and 10 of the 40 melodic trials were borrowed from the mini-PROMS (Kunert et al. 2016) and were used as control. They won't be described here. I will now describe the 30 stimuli that were specifically designed for the present study. All of them were designed to either respect or not the grammars of Western and Carnatic music. They break down into two main categories:

(i) 12 stimuli were created with a computer sound, the same as in PROMS and miniPROMS: the "harpsichord" timbre from Logic Pro. This sound has been selected because it is clear, distinct, and relatively neutral, i.e., less familiar to most listeners compared to the sounds of other instruments (Law and Zentner 2012: 4). These 12 stimuli were composed of monophonic melodies with constant rhythms (10-18 eighth notes), as in Figure 10.4 below. 3 of these 12 trials were designed to only be grammatical in Carnatic music: they were based on raagam (grammatical in Carnatic music) that do not fit in the Western major/minor modes (ungrammatical in Western classical music). 3 of these 12 trials were based on raagam chosen so that they, by contrast, fit in the Western major/minor modes (grammatical in both Western and Carnatic music). These 3 stimuli were thus supposed to be as neutral as Logic Pro "harpsichord" melodies can be with respect to the two musical cultures ${ }^{15} .3$ of these 12 trials trials were constituted of modulations (harmonic sequences) and designed to respect Western musical grammar, but not Carnatic musical grammar: as said above (section 2.2.), modulations are considered ungrammatical in Carnatic music (Vijayakrishnan, 2007: 71), but are common in Western classical music. Finally, 3 of these 12 trials trials were designed to respect neither Western nor Carnatic systems: they were constituted of completely atonal melodies, not fitting in any raaga or Western mode.

\footnotetext{
${ }^{15}$ Which, of course, is not completely neutral: Logic Pro has been designed for Western music and its sounds are thus biased (e.g. they use equal temperament tuning, they don't allow for shrutis, notes' are attacked staccato, etc.) Still: Indian music students often use Western keyboards to learn music and so the biased might not be so strong.
} 
Figure 10.4. Examples of melodic stimuli. These figures show the transcription of the stimuli of two trials where reference and comparison stimuli are different. The difference in the bottom trial is harder to detect than in the top one because the melodic structure is atonal (differences are marked with $\mathrm{a}^{*}$ ).

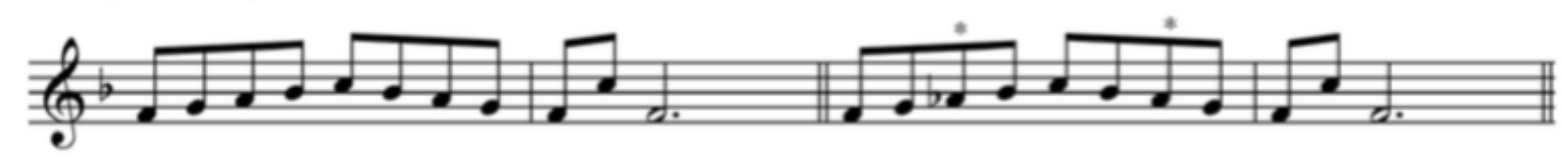

Reference stimulus Comparison stimulus

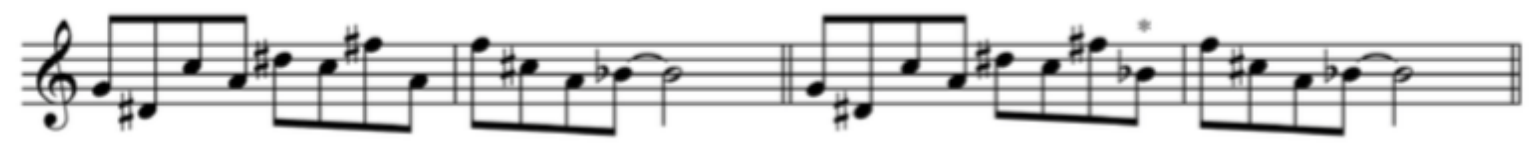

Reference stimulus Comparison stimulus

(ii) 18 stimuli were recordings of violin played either by a Western semi-professional violinist (Mathieu Orioli) or a Carnatic professional violinist (Lalitha Raghavan). Each of these 18 trials were were based on the 18 violin pieces used in the second part of our study (see below). Thus 9 were exctracted from the Western classical repertoire and 9 from traditional Carnatic playing. An example is given in Figure 10.5.

Figure 10.5. A reference and comparison stimulus selected from the Mozart extract (see below).

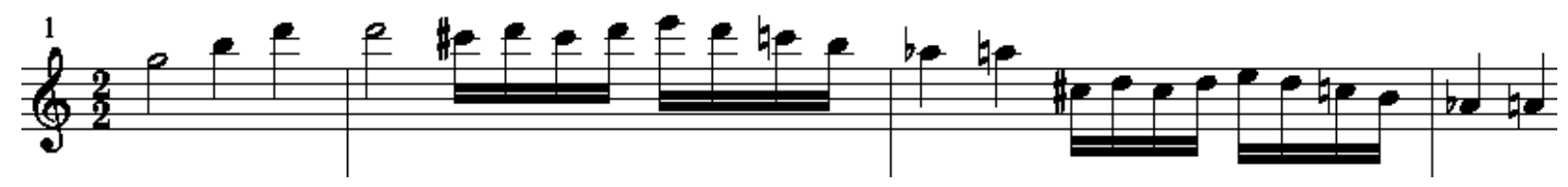

Reference stimulus

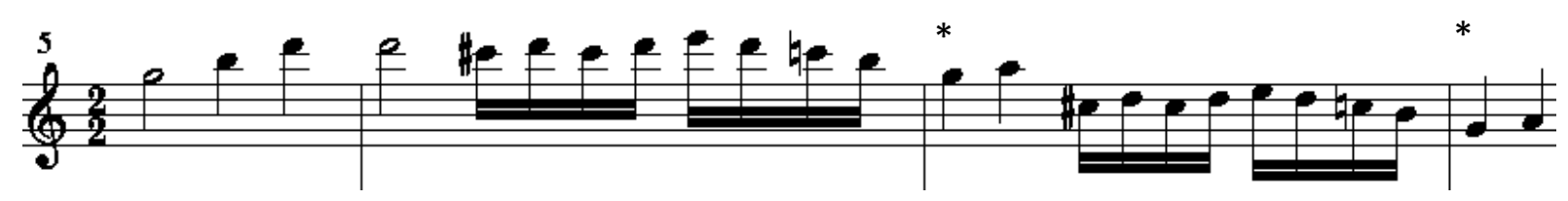

Comparison stimulus (different notes are marked with a *) 
We used both violin and computer-generated stimuli because each has its advantages and disadvantages. The main advantage for recorded violin is that they are more ecological: in Carnatic and Western music, the way instruments are played differ widely, even if it is the same instrument. This is an important part of what makes these music unique, and the way instruments are played is certainly part of their grammar (on a phonological or prosodic level). The main disadvantage is that it is hard to control for each of the parameters that vary between the comparison and reference stimuli. A violinist might attempt to play the same melody twice and, even though it would sound the same to his or her ears, a slight difference might persist. For the violin stimuli, participants were asked to judge whether the notes of the melody in the reference and comparison stimuli were the same or different, and to ignore any difference in rhythm, tuning, or interpretation. Still, human error brings in unknown variables. The main advantage of computer generated stimuli, on the other hand, is that we can control for each of the parameters that are modified in the comparison and reference stimuli. The main disadvantage is that these sounds are unnatural to both grammar, and especially to Carnatic music. This asymmetry is not surprising since Logic Pro is a computer program designed to reproduce Western music, which unfortunately is the case for any standard music computer program.

As explained above, our overall expectation for these 30 melody trials was the following: for someone who is more familiar with a given musical idiom, the melodic structures which are grammatical in this idiom will be easier to encode. Thus, we expected that Carnatic musicians would be better than Western musicians at identifying melodic trials that do not fit in the Western modes, but fit in Carnatic raagam, while Western musicians would be better than Carnatic musicians for the melodic trials that display modulations.

As data collection ended a few days before this chapter was submitted, the analyses presented here are only preliminary. We took participants' scores (reflecting their performance at the task consisting in determining whether the reference and comparison stimuli were the same) and looked at how they were impacted by the type of music (Western vs. Carnatic) and the demographic origin of participants (Switzerland vs. India). To this end, we conducted a 3way ANOVA with scores as a dependent variable and the three following factors: (i) whether the stimuli respected the rules of Western music, (ii) whether the stimuli respected the rules of Carnatic music, and (iii) the participants' demographic origin. We hypothesized that the first two factors would interact with the third, so that music that stimuli that respect Western or 
Carnatic rules would yield higher scores, but that this effect would be greater for European participants in the case of Western music, and greater for Indian participants in the case of Carnatic music.

As predicted, we found an interaction effect between stimuli's respect of Western rules and participants' demographic origins: $F(1,75)=17.08, p<0.001$. Music that respected Western norms were more easily recognized $(F(1,75)=126.82, p<.001$, but the score increase was higher for European participants than for Indian participants (see Table 10.1). However, contrary to our prediction, we found no interaction between stimuli's respect of Carnatic rules and participants' demographic origins: $F(1,75)=0.81, p=0.37$. Music that respected Carnatic rules was also more easily recognized $(F(1,75)=42.87, p<.001)$, but the extent of this facilitation did not differ between European and Indian participants. We venture that this asymmetry between Western and Carnatic stimuli might be due to three factors, which could have combined: (i) As said above the computer generated stimuli do not reflect Carnatic music as well as Western music, the Carnatic stimuli might thus have sound "foreign" even to familiar Carnatic listeners. Less foreign than the atonal stimuli, but as much as the Western ones. (ii) Concerning the violin stimuli, the human error variable discussed above might have been greater in the Carnatic stimuli, making them unfit to measure participant's familiarity to Carnatic music. (iii) Concerning the violin stimuli again, since Carnatic music is not a fully written music, it is more ambiguous than in Western music whether the notes of two melodies played on an instrument are the same or not, both for musicians and for listeners. This might have been a source of confusion, especially for the Indian musician participants. In Western music, the notes of two melodies are different if and only if they wouldn't be written with the same symbols on a score. Carnatic music uses no score and the concept of a note in this tradition is not as agreed upon as in Western classical music. For instance, there is an ongoing debate as to how many shruti, or embellishment notes, there are (see Datta et al 2006 and section 2.2. above).

In any case, for both Indian and Western populations, the Western and atonal stimuli confirmed the expectation that it would be easier for someone who is more familiar with a given musical idiom to encode the melodic structures which are grammatical in this idiom, a result which makes a lot of sense from the musicalanguage hypothesis.

Table 10.1. Results for the first part of the study (participants' scores to the recognition task, in function of the type of music and participants' demographic origin). 


\begin{tabular}{|l|l|l|l|l|}
\hline \multirow{2}{*}{} & \multicolumn{2}{|l|}{ Western rules } & \multicolumn{2}{l|}{ Carnatic rules } \\
\cline { 2 - 5 } & European part. & Indian part. & European part. & Indian part. \\
\hline Respected & $1.14(0.66)$ & $0.49(0.72)$ & $0.84(0.84)$ & $0.42(0.74)$ \\
\hline Not respected & $0.10(0.53)$ & $0.14(0.57)$ & $0.40(0.67)$ & $0.08(0.60)$ \\
\hline
\end{tabular}

\subsection{Second Hypothesis: familiarity and judgment of emotions expressed by music}

In the second part of the experiment, participants were presented with 18 extracts of pieces for solo violin of one minute each. Their task was to rate continually, while the music was playing, how much they thought the music expressed a given affective dimension (see Tables 10.2 and 10.3 below for the affective dimensions in question, more on this later). They did so for each of the twelve 5-second slots of the one-minute pieces. This real-time methodology was a pen and paper adaptation of the 'dynamic judgment' framework developed in Torres-Eliard et al. (forthcoming). This dynamic method allows for the investigation of the attribution of emotional characteristics to music in a very precise manner. Hence, through the judgment of competent listeners, this allows for a detailed investigation of what I called above the affective meaning of music.

The 9 target affective dimensions are the ones composing the Geneva Emotional Music Scale (GEMS) developed by Zentner, Scherer, and Grandjean (2008). These 9 dimensions have been selected through an elaborate empirical process whose goal was to select, from an initial list of about 400 items, the terms which best reflect the affects most frequently expressed and evoked by music. I used the GEMS model as it currently represents the most effective attempt to study affective dimensions related to music (Torres-Eliard et al. forthcoming).

For this second part of the study, the stimuli consisted in extracts from the Carnatic and Western classical music traditions played on a solo violin. The Western classical music extracts were played by renown violinist René Capuçon. The Carnatic music extracts were played by professional violinist Lalitha Raghavan. I chose to use a solo instrument because accompaniment in Western and Carnatic are too dissimilar. The violin was the obvious choice as it is an instrument that belongs to the core of both these musical traditions. Recorded extracts of professional musicians playing solo violin thus constituted a culturally neutral, sufficiently expressive, and musically ecological medium. 
Apart from these criteria, these extracts were selected because of their expressive qualities. Each of the 9 Western extracts and each of the 9 Carnatic extracts target one of the 9 affective dimensions of the GEMS (see Tables 1 and 2 below). The 9 Western classical music extracts had already been selected to target the 9 GEMS dimensions in a previous study in which their capacity to evoke the targeted affective dimensions was confirmed (Labbé and Grandjean 2014). I used the same recordings.

Table 10.2. Western classical music pieces used in this study and the GEMS affective dimension they target.

\begin{tabular}{|c|c|}
\hline Piece (first 1 min. of each) & Target GEMS Dimension \\
\hline Bach, Partita no. 2 in D minor, BWV 1004, I. & Nostalgic, sentimental \\
\hline Beethoven, Violin concerto in D major, Op. 61, II. & Relaxed, peaceful \\
\hline Franck, Sonata for piano \& violin in A major, FWV \\
8, II. & Melancholic, sad \\
\hline Glück, 'Melody" from Orpheus \& Eurydice & Full of tenderness, \\
\hline warmhearted \\
\hline Massenet, "Méditation', from Thaïs & Moved, touched \\
\hline 64, I. & Tense, uneasy \\
\hline Mozart, Violin concerto no. 3 in G major, K. 216, I. & Joyful, lively \\
\hline Schumann, Violin concerto in D minor, Op. & Powerful, strong \\
\hline Posth., I. & Filled with wonder, amazed \\
\hline
\end{tabular}

The 9 Carnatic music extracts were selected and designed by K.G. Vijayakrishnan and Lalitha Raghavan. Representative of Carnatic music practice, these extracts were either improvisations based on previous compositions or free improvisations (aalaapanai and/or taanam). Like the Western stimuli, each of them targeted one of the 9 GEMS dimensions. 
Table 10.3. Carnatic music pieces used in this study and their targeted GEMS affective dimension.

\begin{tabular}{|c|c|c|}
\hline Type of composition and/or improvisation & Raagam & $\begin{array}{l}\text { Target GEMS } \\
\text { Dimension }\end{array}$ \\
\hline $\begin{array}{l}\text { The čaraNam of Tanjai Naalvar's } \\
\text { composition 'Amba Niilaambari' rendered } \\
\text { as semi- free variation }\end{array}$ & Niilaambari & $\begin{array}{l}\text { Nostalgic, } \\
\text { sentimental }\end{array}$ \\
\hline A mix of aalaapanai and taanam & Reevagupti & Relaxed, peaceful \\
\hline Aalaapanai & Nadanamakriya & Melancholic, sad \\
\hline $\begin{array}{l}\text { A free rendering of the swara-saahityam of } \\
\text { Subbaraya Shastri composition 'Eemaninne' }\end{array}$ & Mukhaari & $\begin{array}{l}\text { Full of tenderness, } \\
\text { warmhearted }\end{array}$ \\
\hline $\begin{array}{l}\text { The 'Anupallavi' of Maayamma/Shyama } \\
\text { Shastri composition rendered as a free, } \\
\text { arrhythmic variation. }\end{array}$ & Aahiri & Moved, touched \\
\hline $\begin{array}{l}\text { Free rendering of a part of the Tillaanaa } \\
\text { composed by Lalgudi Jayaraman }\end{array}$ & Tilang & Tense, uneasy \\
\hline A mix of aalaapanai and taanam & Moohanam & Joyful, lively \\
\hline A mix of taanam and aalaapanai & AThaaNaa & Powerful, strong \\
\hline $\begin{array}{l}\text { The chittaswaram of the Tygaraja composition } \\
\text { 'Nenarunci naanu' }\end{array}$ & MaaLavi & $\begin{array}{c}\text { Filled with } \\
\text { wonder, amazed }\end{array}$ \\
\hline
\end{tabular}

Our general expectation for this section were the following: Western musicians will be better at recognizing what affective dimensions are expressed in the Western extracts and Indian participants will be better at recognizing what affective dimensions are expressed in the Carnatic extracts. From the musicalanguage hypothesis perspective, the idea here is that participants more familiar with a given idiom will better understand what the musical utterances in this idiom are meant to express, better at understanding the musical affective meaning. 
Quantitatively, given the available data, this translates in several ways. We will just concentrate on the most straightforward analysis, without taking into account differences between the 9 GEMS dimensions, or the time-curves resulting from the 5-second slots dynamic judgments. These further analyses will be available in Bonard et al (forthcoming).

The hypothesis examined here was that Western participants would judge Western music as more expressive than Carnatic music and vice versa. To test for this hypothesis, we ran a 2-way ANOVA with participants' expressiveness judgments as a dependent variable and two factors: (i) the type of music (Western vs. Carnatic), and (ii) the participants' demographic origin (European vs. Indian).

We indeed observed an interaction effect: European participants judged Western music as more expressive than Indian participants, while Indian participants judged Carnatic music more expressive than European participants: $F(1,73)=3.84, p<.001$. (see Table 10.4.)

Table 10.4. Results for the second part of the study (participants' expressiveness scores in function of type of music and participants' demographic origin).

\begin{tabular}{|l|l|l|}
\hline & Western music & Carnatic music \\
\hline European participants & $3.38(0.51)$ & $3.10(0.58)$ \\
\hline Indian participants & $2.80(0.69)$ & $3.16(0.68)$ \\
\hline
\end{tabular}

\subsection{Further question: do you need to have learned the musical grammar of an idiom in order to understand its musical meaning?}

In the previous sections, we have seen that familiarity with a certain kind of music (i) can improve one's understanding of its grammar, and (ii) can improve one's perception of expressiveness. In light of these results, my overall hypothesis is that differences in the perception of affective expression - that is, differences in understanding musical meaning might be partially explained by different levels of grammatical mastery. Just as with linguistic idioms, and despite the fact that music lacks vocabulary, a mastery of the idiom's grammar would ground the ability to understand and express meaning. This is tantamount to saying that, as Westerners, we understand our classical music better than Carnatic music because we have 
a poorer grammatical knowledge of Carnatic music, it being a foreign musical idiom. If this hypothesis is correct, it would in turn explain some cultural asymmetries in musical tastes and aesthetics, why people tend to better understand the values of musical idioms with which they are more familiar. Perhaps even why someone who has not grown up listening to rap music might find it difficult to understand what is interesting about it, musically speaking, compared with someone for whom rap is like a musical mother tongue. Further empirical studies are needed to explore these more general and exciting hypotheses.

\section{General conclusion}

In this chapter, I have briefly introduced the notion of musical grammar and its relation to meaning in music. I have situated those concepts in a theoretical framework emphasizing the similarities between music and language and highlighting the fact that they have an important overlap of cognitive properties. I have then presented the musicalanguage hypothesis, which states that music makes use of cognitive mechanisms traditionally ascribed to linguistic phonetics, phonology, prosody, semantics, syntax, and pragmatics.

Within this framework, I have described an empirical study that I am conducting between two musical idioms: Western and South Indian classical music. This study focuses on their grammatical differences. I have shown that it is possible to formulate testable hypotheses about musical grammar and musical meaning by testing perception of musical structures and affective expressions in populations with different levels of mastery for the two musical idioms.

The full results of this study are not yet available, and I have been only able to present preliminary analyses of our findings. However, irrespective of whether the hypotheses given above are falsified or corroborated, they should be of interest to music researchers, especially because of this study's cross-cultural take, an area of research where empirical data is crucially lacking, but which bears on important issues in the aesthetics of music.

Regardless of the empirical results that this study will yield, I hope to have been convincing in arguing that the similarities between language and music should be taken seriously. Combining insights from Romantic philosophers and cognitive scientists is a promising research program in aesthetics and allows a fresh look at old philosophical problems from an experimental perspective. 


\section{References}

Bonard, C., Grandjean, D., and Vijayakrishnan, K.G. (in preparation). "Do you need a musical grammar to understand musical meaning? Measuring the perception of melodies and emotions expressed in Western and South Indian classical music by South Indians and Westerners" (Title subject to change).

Brown, S., Martinez, M., and Parsons, L.. "Music and language side by side in the brain: a PET study of the generation of melodies and sentences." European journal of neuroscience 23.10 (2006): 2791-2803.

Datta, A. K., Sengupta, R., Dey, N., \& Nag, D. (2006). Experimental analysis of shrutis from performances in Hindustani music. Scientific Research Department, ITC Sangeet Research Academy.

Davies, S. (2003). Themes in the Philosophy of Music. Oxford University Press, Oxford.

Domardzki, M. (2007). A Cognitive Critique of Generative Grammar. http://www.lingua.amu.edu.pl/Lingua_17/lin-4.pdf

Dowling, W.J., Kwak, S., Andrews, M.W. (1995). "The time course of recognition of novel melodies", Attention Perception Psychophysics 57: 136-149.

Dummett, M. (1973). Frege: Philosophy of Language. Harper \& Row, New York.

Granroth-Wilding, M., \& Steedman, M. (2014). A robust parser-interpreter for jazz chord sequences. Journal of New Music Research, 43(4), 355-374.

Grice, P. (1957). "Meaning", Philosophical Review, 66(3).

Hauser, M. D., Chomsky, N. and Fitch, W. T. (2002). "The faculty of language: what is it, who has it and how did it evolve?", Science, 298, 1569-1579.

Kania, A., "The Philosophy of Music", The Stanford Encyclopedia of Philosophy (Winter 2016 Edition), Edward N. Zalta (ed.), URL = $<$ https://plato.stanford.edu/archives/win2016/entries/music/>.

Katz, J. \& Pesetsky, D. (2011). “The Identity Thesis for Language and Music”, (online version: http://ling.auf.net/lingbuzz/000959). 
Koelsch, S., and Siebel, W. (2005). "Towards a neural basis of music perception." Trends in cognitive sciences, 9.12: 578-584.

Kunert, R., Willems, R. M., Casasanto, D., Patel, A. D., \& Hagoort, P. (2015). "Music and language syntax interact in Broca's area: an fMRI study". PloS one, 10(11), e0141069.

Kunert R., Willems R. M., Hagoort, P. (2016). “An Independent Psychometric Evaluation of the PROMS Measure of Music Perception Skills". PLoS ONE 11(7): e0159103.

Labbé, C. and Grandjean, D. (2014). "Musical Emotions Predicted by Feelings of Entrainment”. Music Perception, 32 (2), 170-185.

Law, L. and Zentner, M. (2012). “Assessing musical abilities objectively: Construction and validation of the Profile of Music Perception Skills". PloS ONE 7(12): e52508.

Lerdahl, F. (2001). Tonal Pitch Space, Oxford: Oxford University Press.

Lerdahl, F. and Jackendoff, R. (1983). A Generative Theory of Tonal Music. MIT Press, Cambridge (USA).

Levinson, J. (2011). Music, Art, \& Metaphysics, Oxford University Press, Oxford.

O’Grady, W., Dobrovolsky, M., Aronoff, M., Rees-Miller, J. (2017). Contemporary Linguistics: An Introduction (Seventh Edition), Bedford/St. Martin's, Boston/New York.

Patel, A. (2010). Music, Language, and the Brain. Oxford University Press, Oxford.

Raffman, D. (1993). Music, Language, Mind. MIT Press, Cambridge (MA, USA).

Rebuschat, P. et al. (2012). Language and music as cognitive systems. Oxford University Press, Oxford.

Rohrmeier, M., \& Neuwirth, M. (2015). "Towards a Syntax of the Classical Cadence" in What is a Cadence? Theoretical and Analytical Perspectives on Cadences in the Classical Repertoire pages, pp. 285-336, Leuven University Press, Leuven.

Rohrmeier, M., \& Widdess, R. (2016). Incidental Learning of Melodic Structure of North Indian Music. Cognitive Science.

Schlenker, P. (forthcoming) "Outline of Music Semantics". Music Perception. 35, 1: 3-37

Schulze K, Dowling WJ, Tillmann B (2012) Working memory for tonal and atonal sequences during a forward and backward recognition task. Music Perception 29: 255-267. 
Scruton, R. (1997). The Aesthetics of Music. Oxford University Press, Oxford.

Strawson, P.F. (1950). "On referring", Mind, 10 (235).

Torres-Eliard, K., Ott, T, Labbé C., \& Grandjean D. (submitted). "Dynamic Approach to the Study of Emotions Expressed by Music"

Vijayakrishnan, KG. (2007). The Grammar of Carnatic Music, De Gruyter Mouton, Berlin.

Wittgenstein, L. (1953). Philosophical Investigations, Macmillan, New York.

Zentner, M., Scherer, K. \& Grandjean, D. (2008). "Emotions Evoked by the Sound of Music: Characterization, Classification, and Measurement”, Emotion, 8(4): 494-521. 